Revista Brasileira de Agricultura Irrigada v.14, no .4, p. 4118 - 4127, 2020

ISSN 1982-7679 (On-line)

Fortaleza, CE, INOVAGRI - http://www.inovagri.org.br

DOI: $10.7127 /$ rbai.v14n401173

Protocolo 1173.20 - 22/09/2020 Aprovado em 26/01/2021

\title{
ADUBAÇÃO NITROGENADA POR DIFERENTES MÉTODOS NO CULTIVO DA ABOBRINHA IRRIGADA
}

Carlos Newdmar Vieira Fernandes ${ }^{1}$, Benito Moreira de Azevedo ${ }^{2}$, Denise Vieira Vasconcelos ${ }^{3}$, Chrislene Nojosa Dias Fernandes ${ }^{4}$, José Normand Vieira Fernandes ${ }^{5}$, Thales Vinícius de Araújo Viana $^{2}$

\section{RESUMO}

A abobrinha, cucurbitácea apreciada pelo sabor e textura leve, tem o manejo nutricional como fator relevante para o estabelecimento e incremento produtivo. Objetivando avaliar o efeito de doses de nitrogênio aplicadas convencionalmente e por fertirrigação na abobrinha (Cucurbita pepo L.), realizou-se um experimento em Fortaleza, Ceará. O delineamento utilizado foi o de blocos casualizados, com quatro repetições, em esquema fatorial $(2 \times 4)$, sendo duas formas de adubação (Convencional e Fertirrigação) e quatro doses de nitrogênio (0, 70, 140 e $\left.280 \mathrm{~kg} \mathrm{ha}^{-1}\right)$. Avaliou-se a massa do fruto, número de frutos, comprimento do fruto, diâmetro do fruto, espessura da polpa, sólidos solúveis e produtividade. Avaliou-se também a eficiência de uso da água (EUA) e do nitrogênio (EUN), além da análise econômica por meio do VPL, TIR e "payback". As doses de N influenciaram a massa do fruto, o diâmetro do fruto e a produtividade. A produtividade apresentou ajuste linear crescente, sendo o maior valor estimado $27.302 \mathrm{~kg} \mathrm{ha}^{-1}$, respectivo a maior dose $(280 \mathrm{~kg}$ $\mathrm{ha}^{-1}$ de $\mathrm{N}$ ), dose também responsável pela maior EUA de $68 \mathrm{~kg} \mathrm{ha}^{-1} \mathrm{~mm}^{-1}$. A EUN apresentou comportamento quadrático com a dose de $160 \mathrm{~kg} \mathrm{ha}^{-1}$ de $\mathrm{N}$ proporcionando um valor máximo de (55 $\left.\left(\mathrm{kg} \mathrm{ha}^{-1}\left(\mathrm{~kg} \mathrm{ha}^{-1}\right)^{-1}\right)\right)$. Todos os tratamentos foram economicamente viáveis, sendo os meses de maio, abril, dezembro e novembro os mais promissores.

Palavras-chave: Cucurbita pepo L, quimigação, ureia.

\footnotetext{
${ }^{1}$ Eng. Agrônomo, Prof. Dr., Instituto Federal do Ceará - campus Iguatu, Iguatu, CE. E-mail: newdmar.fernandes@ifce.edu.br

${ }^{2}$ Eng. Agrônomo, Prof. Dr., Universidade Federal do Ceará, Fortaleza, CE. E-mail: benitoazevedo@hotmail.com; thales@ufc.br

${ }^{3}$ Eng. Agrônoma, Prof. Dra., Instituto Federal do Pará - campus Bragança, Bragança, PA. E-mail: denisevasconcelos@gmail.com

4 Eng. Agrônoma, Dra. em Engenharia Agrícola, Universidade Federal do Ceará, Fortaleza, CE. E-mail: chrislene@gmail.com

${ }^{5}$ Eng. Agrônomo, Mestrando em Engenharia Agrícola, Universidade Federal do Ceará, Fortaleza, CE. E-mail: normandvf@gmail.com
} 


\title{
NITROGENATED FERTILIZATION BY DIFFERENT METHODS IN THE GROWTH OF IRRIGATED ZUCCHINE
}

\begin{abstract}
The zucchini, cucurbit appreciated the taste and light texture, has the nutritional management as a relevant factor for the establishment and production increase. To evaluate the effect of nitrogen applied conventionally and fertigation in squash (Cucurbita pepo L.), there was an experiment in Fortaleza, Ceará. The design was a randomized complete block design with four replications in factorial $(2 \times 4)$ and two fertilization ways (conventional and fertigation) and four nitrogen rates $(0$, 70,140 and $280 \mathrm{~kg} \mathrm{ha}^{-1}$ ). Fruit mass, number of fruits, fruit length, fruit diameter, pulp thickness, soluble solids and productivity were evaluated. The efficiency of the use of water (USA) and nitrogen (EUN) was also evaluated, in addition to the economic analysis by means of NPV, IRR and "payback". The doses of $\mathrm{N}$ influenced the fruit mass, fruit diameter and productivity. The yield showed increasing linear fit, the largest estimated $27,302 \mathrm{~kg} \mathrm{ha}^{-1}$, it's the highest dose $\left(280 \mathrm{~kg} \mathrm{ha}^{-1}\right.$ $\mathrm{N}$ ), dose also responsible for the largest US $68 \mathrm{~kg} \mathrm{ha}^{-1} \mathrm{~mm}^{-1}$. NUE presented quadratic behavior with a dose of $160 \mathrm{~kg} \mathrm{ha}^{-1} \mathrm{~N}$ providing a maximum of $\left(55 \mathrm{~kg} \mathrm{ha}^{-1}\left(\mathrm{~kg} \mathrm{ha}^{-1}\right)^{-1}\right)$. All treatments were economically viable, and the months of May, April, December and November the most promising.
\end{abstract}

Key words: Cucurbita pepo L, Chemigation, Urea.

\section{INTRODUÇÃO}

A abobrinha (Cucurbita pepo L.), é uma planta da família Cucurbitaceae, cultivada em todas as regiões do Brasil (COUTO et al., 2009), tendo sua exploração, realizada em pequenas propriedades com mão de obra familiar, contribuindo para a manutenção do homem no campo e estimulando a geração de emprego e renda (COSTA et al., 2015). É também conhecida como abóbora de moita, italiana, ou de tronco (FILGUEIRA, 2012).

No estado do Ceará, de acordo com a análise conjuntural da CEASA, a comercialização da abobrinha é crescente nos últimos anos, com um volume médio comercializado nos anos de 2013 e 2014 de $383,7 \mathrm{t}$ ano $^{-1}$ movimentando um valor médio de R\$ 438.250,02 ano $^{-1}$ no período (CEASA/CE, 2015).

No caso da abobrinha, assim como em outras culturas, para a obtenção de sucesso na produção é necessário um adequado fornecimento de nutrientes desde o estádio de plântula até a colheita, sendo que, o desequilíbrio nutricional, por carência ou excesso de nutrientes, influencia diretamente na produção e na qualidade final do produto (ARAÚJO et al., 2012). Para cucurbitáceas
Silva et al. (2013) observaram que o nitrogênio foi o segundo nutriente mais absorvido pela abóbora, tendo o mesmo fato ocorrido com o melão (SILVA JÚNIOR et al., 2006), e a melancia (ALMEIDA et al., 2012; NOGUEIRA et al., 2014).

Dada a importância do nitrogênio, seu manejo deve ser estudado no sentido de melhorar sua eficiência de uso, pré-requisito para diminuir os custos de produção, para proteção ambiental e aumento no rendimento das culturas. A quantidade de $\mathrm{N}$ a ser aplicada deve minimizar tanto os excessos, que prejudicam a qualidade ambiental e cultural e oneram o produtor, quanto os déficits, que comprometem o rendimento projetado.

Para se estabelecer as demandas específicas de cada cultura, estudos relacionados a doses de fertilizantes são necessários (ARAÚJO et al., 2012), uma vez que, resultados diferentes podem ser obtidos em função da forma de aplicação do adubo nitrogenado, da cultivar utilizada, do manejo da irrigação e das condições edafoclimáticas locais (ARAÚJO et al., 2011). Em cucurbitáceas, o aumento da dose de $\mathrm{N}$, até determinado limite, proporciona incremento na área foliar da planta, exercendo efeito na produção de fotoassimilados e, 
consequentemente, na produção de frutos (QUEIROGA et al., 2007).

Com relação à forma de aplicação do adubo, no método convencional, onde a aplicação é feita a lanço ou em sulco, estimase que apenas $1 / 3$ dos adubos nitrogenados aplicados é aproveitado pelas plantas, o restante perdido por lixiviação, escoamento superficial e volatilização. A aplicação de fertilizantes via água de irrigação, pode reduzir ou eliminar tais perdas, pois o nutriente é fornecido no momento e em quantidade adequada para as plantas, aumentando a eficiência e o aproveitamento dos adubos (ANDRADE JÚNIOR et al., 2006).

A fertirrigação tem possibilitado a otimização do uso de fertilizantes, com melhorias na produtividade e qualidade dos produtos, sendo mais notável sua adoção em culturas irrigadas por sistemas localizados (OLIVEIRA; VILLAS BÔAS, 2008). Nesse sentido, alguns pesquisadores vêm estudando a resposta de diferentes culturas às doses de nutrientes aplicadas pelo método convencional e por fertirrigação, como Nascimento Neto et al. (2012) na cultura do meloeiro amarelo e Sousa et al. (2013) na cultura do amendoim.

Assim, o presente trabalho teve como objetivo avaliar o efeito de doses de nitrogênio aplicadas de forma convencional e via fertirrigação por gotejamento na cultura da abobrinha.

\section{MATERIAL E MÉTODOS}

O experimento foi conduzido no período de setembro a novembro de 2013, na área experimental da Estação Meteorológica da Universidade Federal do Ceará (UFC), em Fortaleza, Ceará, Brasil, a $3^{\circ} 44^{\prime}$ de latitude sul, 38 $33^{\circ}$ ' de longitude oeste e $19,5 \mathrm{~m}$ de altitude.

O clima da região é do tipo Aw', tropical chuvoso, com precipitações predominantes no verão-outono, (KÖPPEN, 1923). Os dados médios mensais das variáveis climáticas durante o período experimental estão apresentados na Tabela 1.

Tabela 1. Dados médios mensais das variáveis climáticas mensurados durante a condução do experimento, Fortaleza, Ceará, 2013.

\begin{tabular}{lccccc}
\hline \multicolumn{1}{c}{ Mês } & $\begin{array}{c}\text { Temperatura } \\
\text { do } \operatorname{ar}\left({ }^{\circ} \mathrm{C}\right)\end{array}$ & $\begin{array}{c}\text { Umidade Relativa do } \\
\operatorname{ar}(\%)\end{array}$ & $\begin{array}{c}\text { Velocidade do Vento } \\
\left(\mathrm{m} \mathrm{s}^{-1}\right)\end{array}$ & $\begin{array}{c}\text { Precipitação } \\
(\mathrm{mm})\end{array}$ & $\begin{array}{c}\text { EToPM } \\
(\mathrm{mm})\end{array}$ \\
\hline Setembro & 27,1 & 64 & 4,4 & 16,7 & 5,96 \\
Outubro & 27,5 & 75 & 4,5 & 10,1 & 6,08 \\
Novembro & 27,5 & 68 & 4,3 & 5,7 & 5,76 \\
\hline Média & 27,4 & 69 & 4,4 & 10,83 & 5,93 \\
\hline
\end{tabular}

Fonte: Estação Meteorológica da Universidade Federal do Ceará

$\begin{array}{lllr} & \text { O solo da } & \text { área } & \text { experimental } \\ \text { é } & \text { classificado } & \text { como } & \text { Argissolo }\end{array}$

Vermelho-Amarelo (EMBRAPA, 2006), cujos atributos químicos e físicos do solo, na camada 0-0,2 m estão apresentados na Tabela 2 .

Tabela 2. Atributos químicos e físicos do solo da área experimental, na camada de 0 a $0,2 \mathrm{~m}$.

\begin{tabular}{|c|c|c|c|}
\hline Atributos Químicos & & Atributos Físicos & \\
\hline $\mathrm{P}\left(\mathrm{mg} \mathrm{dm}^{-3}\right)$ & 6,00 & Areia fina $\left(\mathrm{g} \mathrm{kg}^{-1}\right)$ & 386 \\
\hline $\mathrm{K}^{+}\left(\mathrm{cmol}_{\mathrm{c}} \mathrm{dm}^{-3}\right)$ & 0,11 & Areia grossa $\left(\mathrm{g} \mathrm{kg}^{-1}\right)$ & 405 \\
\hline $\mathrm{Na}^{+}\left(\mathrm{cmol}_{\mathrm{c}} \mathrm{dm}^{-3}\right)$ & 0,06 & Silte $\left(\mathrm{g} \mathrm{kg}^{-1}\right)$ & 96 \\
\hline $\mathrm{Ca}^{2+}\left(\mathrm{cmol}_{\mathrm{c}} \mathrm{dm}^{-3}\right)$ & 1,70 & Argila $\left(\mathrm{g} \mathrm{kg}^{-1}\right)$ & 113 \\
\hline $\mathrm{Mg}^{2+}\left(\mathrm{cmol}_{\mathrm{c}} \mathrm{dm}^{-3}\right)$ & 1,20 & Classe textural & Franco-arenosa \\
\hline $\mathrm{H}^{+}+\mathrm{Al}^{3+}\left(\mathrm{cmol}_{\mathrm{c}} \mathrm{dm}^{-3}\right)$ & 1,65 & Massa específica do solo $\left(\mathrm{g} \mathrm{cm}^{-3}\right)$ & 1,43 \\
\hline $\mathrm{Al}^{3+}\left(\mathrm{cmol}_{\mathrm{c}} \mathrm{dm}^{-3}\right)$ & 0,10 & Massa específica das partículas $\left(\mathrm{g} \mathrm{cm}^{-3}\right)$ & 2,57 \\
\hline $\mathrm{pH}$ & 5,60 & Capacidade de campo $\left(\mathrm{g} 100 \mathrm{~g}^{-1}\right)$ & 7,52 \\
\hline $\mathrm{CE}\left(\mathrm{dS} \mathrm{m} \mathrm{m}^{-1}\right)$ & 0,20 & Ponto de murcha permanente $\left(\mathrm{g} 100^{-1}\right)$ & 4,52 \\
\hline
\end{tabular}

Fonte: Laboratório de Solos e Água, do Departamento de Ciências do Solo do CCA/UFC. 
A quantificação dos adubos foi realizada de acordo com a análise do solo da área (Tabela 2) e com as recomendações propostas por Filgueira (2012). As doses de nutrientes e fontes comerciais utilizadas foram: $140 \mathrm{~kg} \mathrm{ha}^{-1}$ de nitrogênio (Ureia - 45\% de N); $300 \mathrm{~kg} \mathrm{ha}^{-1}$ de fósforo (Superfosfato simples - $18 \%$ de $\mathrm{P}_{2} \mathrm{O}_{5}$ ), além de $2 \mathrm{~kg} \mathrm{ha}^{-1}$ de boro (ácido bórico - $17 \%$ de Boro). A quantidade de nitrogênio aplicada variou em função de cada tratamento utilizando como fonte a ureia $(45 \%$ de $\mathrm{N})$.

Utilizou-se o delineamento estatístico de blocos casualizados, com quatro blocos, em esquema fatorial $(2 \times 4)$, sendo dois métodos de adubação (Convencional e Fertirrigação) e quatro doses de nitrogênio 0 (controle), $70 \mathrm{~kg}$ $\mathrm{ha}^{-1}$ (metade da dose recomendada), $140 \mathrm{~kg} \mathrm{ha}^{-}$ ${ }^{1}$ (dose recomendada) e $280 \mathrm{~kg} \mathrm{ha}^{-1}$ (dobro da dose recomendada). $\mathrm{Na}$ adubação convencional, as três doses de nitrogênio foram divididas em três aplicações, sendo um terço em fundação e os dois terços restantes em cobertura, no $15^{\circ}$ e no $30^{\circ}$ DAP (Dia Após o Plantio). Nos tratamentos de fertirrigação, as doses de $\mathrm{N}$ foram aplicadas parceladamente, por meio de nove aplicações semanais, com a primeira aplicação no $7^{\circ} \mathrm{DAP}$.

$\mathrm{A}$ área individual da parcela experimental era de $3,6 \mathrm{~m}^{2}(3,6 \mathrm{~m} \times 1,0 \mathrm{~m})$, constituída por 6 plantas com espaçamento de $1,0 \times 0,6 \mathrm{~m}$, correspondendo a um estande de 16.666 plantas ha ${ }^{-1}$. A instalação da cultura da abobrinha (Cucurbita pepo L.) foi realizada por meio de semeadura direta no solo, utilizando o híbrido Corona F1.

O sistema de irrigação foi do tipo gotejamento, com linhas laterais compostas de tubos de polietileno com gotejadores inseridos e espaçados a $0,6 \mathrm{~m}$ e vazão de $4 \mathrm{~L} \mathrm{~h}^{-1}$. Foi instalada uma linha lateral por fileira de planta, cada uma com 3,6 m de comprimento e espaçada em $1,0 \mathrm{~m}$.

O manejo da irrigação consistiu em irrigações diárias, com as lâminas aplicadas estimadas través do método de PenmanMonteith FAO.

Após as colheitas foram analisadas as variáveis: massa do fruto $(\mathrm{MF})$, número de frutos $(\mathrm{NF})$, comprimento do fruto $(\mathrm{CF})$, diâmetro do fruto (DF), espessura da polpa
(EP), sólidos solúveis (SS) e produtividade (PROD).

As variáveis analisadas foram submetidas à análise de variância pelo teste $\mathrm{F}$ $(\mathrm{P}<0,01$ e $\mathrm{P}<0,05)$ e quando verificado efeito significativo na análise de variância, os dados foram submetidos ao estudo de regressão. As análises estatísticas foram executadas com o auxílio dos softwares Microsoft Office Excel (2010) e Assistat 7.7.

A eficiência de uso da água (EUA) foi calculada utilizando-se a equação 1 .

$\mathrm{EUA}=\frac{\mathrm{Y}}{\mathrm{W}}$

Em que: EUA - eficiência do uso da água, $\mathrm{kg}$ $\mathrm{ha}^{-1} \mathrm{~mm}^{-1} ; \mathrm{Y}$ - rendimento da cultura, $\mathrm{kg} \mathrm{ha}^{-1}$, e W - lâmina total de água aplicada durante o ciclo, $\mathrm{mm}$.

A eficiência de uso do nitrogênio (EUN) foi calculada utilizando-se a equação 2 :

$\mathrm{EUN}=\frac{\mathrm{Y}_{\mathrm{t}}-\mathrm{Y}_{0}}{\mathrm{~K}_{\mathrm{t}}}$

Em que: EUN - eficiência do uso do

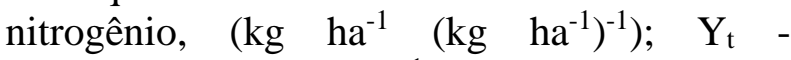
produtividade, $\mathrm{kg} \mathrm{ha}{ }^{-1}$, da abobrinha no tratamento ' $\mathrm{t}$ '; $\mathrm{Y}_{0}$ - produtividade, $\mathrm{kg} \mathrm{ha}^{-1}$, da abobrinha no tratamento testemunha e $\mathrm{Kt}$ quantidade de $\mathrm{N}, \mathrm{kg} \mathrm{ha}^{-1}$, no tratamento ' $\mathrm{t}$ '.

A análise econômica foi realizada por meio dos indicadores: valor presente líquido (VPL); taxa interna de retorno (TIR) e período "payback" (PP). Para isso um fluxo de caixa no período de cinco anos foi construído para analisar a viabilidade econômica da exploração da abobrinha irrigada na região de estudo, levando em consideração as despesas com a produção da cultura; os custos da propriedade e dos equipamentos e as receitas obtidas, que foram calculadas mediante a produtividade estimada para a abobrinha, obtida em um hectare cultivado com dois ciclos anuais.

Os preços dos insumos e equipamentos foram levantados em lojas agropecuárias de Fortaleza, em setembro de 2013. O preço do 


\section{ADUBAÇÃO NITROGENADA POR DIFERENTES MÉTODOS NO CULTIVO DA ABOBRINHA IRRIGADA}

quilograma de abobrinha usado nos cálculos foi referente a $60 \%$ daquele praticado na compra pelos comerciantes da CEASA de Fortaleza, Ceará, no mês de novembro de 2013, mês em que foi realizada a colheita dos experimentos.

Em função da variação mensal dos preços de venda dos frutos, foi realizado ainda o cálculo do VPL para todos os meses do ano, a fim de analisar quais os melhores meses para que o produtor oferte seu produto.

\section{RESULTADOS E DISCUSSÃO}

As doses de nitrogênio influenciaram significativamente a massa do fruto $(p<0,01)$, além do diâmetro do fruto $\mathrm{e}$ a produtividade $(\mathrm{p}<0,05)$ (Tabela 3).

Não houve efeito para os métodos de adubação, sendo a interação significativa apenas para massa do fruto $(\mathrm{p}<0,01)$.

Tabela 3. Resumo da análise de variância para massa do fruto (MF), número de frutos (NF), comprimento do fruto (CF), diâmetro do fruto (DF), espessura da polpa (EP), sólidos solúveis (SS) e produtividade (PROD) da abobrinha em função de doses e formas de aplicação de nitrogênio.

\begin{tabular}{lcccccccc}
\hline \multirow{2}{*}{ FV } & GL & \multicolumn{7}{c}{ Quadrado médio } \\
\cline { 3 - 9 } & & MF & NF & CF & DF & EP & SS & PROD \\
\hline Métodos (M) & 1 & $87^{\text {ns }}$ & $0,0006^{\text {ns }}$ & $1,50^{\text {ns }}$ & $3,06^{\text {ns }}$ & $0,14^{\text {ns }}$ & $0,03^{\text {ns }}$ & $270.237^{\text {ns }}$ \\
Doses (D) & 3 & $51.542^{* *}$ & $0,16^{\text {ns }}$ & $9,44^{\text {ns }}$ & $92,69^{*}$ & $7,39^{\text {ns }}$ & $0,22^{\text {ns }}$ & $112.598 .552^{*}$ \\
M x D & 3 & $65^{* *}$ & $0,17^{\text {ns }}$ & $2,69^{\text {ns }}$ & $7,21^{\text {ns }}$ & $1,59^{\text {ns }}$ & $0,03^{\text {ns }}$ & $12.844 .152^{\text {ns }}$ \\
Blocos & 3 & $58.120^{* *}$ & $1,22^{* *}$ & $1,64^{\text {ns }}$ & $72,02^{\text {ns }}$ & $6,54^{\text {ns }}$ & $0,01^{\text {ns }}$ & $299.653 .084^{* *}$ \\
Resíduo & 21 & 6.806 & 0,12 & 3,20 & 26,16 & 3,03 & 0,08 & 24.214 .679 \\
\hline \multicolumn{1}{c}{ Total } & 31 & - & - & - & - & - & - & - \\
\hline \multicolumn{1}{c}{ CV\% } & - & 13,73 & 16,22 & 8,11 & 7,02 & 12,27 & 9,39 & 21,99 \\
\hline
\end{tabular}

***ignificativo a 0,01 pelo teste $\mathrm{F}$; * significativo a 0,05 pelo teste F; ${ }^{\text {(n) }}$ não significativo pelo teste F. FV - Fonte de variação; GL Grau de liberdade.

Nascimento et al. (2012), testando diferentes doses e formas de aplicação de nitrogênio em melão, não observaram efeito significativo para as variáveis diâmetros polar e equatorial dos frutos. Também em melão, Coelho et al. (2003) não observaram influência da aplicação de nitrogênio no teor de sólidos solúveis do fruto. Para o pepino africano, Antunes et al. (2014) não observaram efeito significativo das doses de $\mathrm{N}$ testadas nas características comprimento do fruto e sólidos solúveis.

$\mathrm{Na}$ Figura 1 observa-se $\mathrm{o}$ comportamento da massa do fruto em função das diferentes doses de nitrogênio aplicadas convencionalmente e via fertirrigação.

Em ambas as formas de aplicação, o modelo polinomial quadrático apresentou-se como o mais adequado, com $\mathrm{R}^{2}$ igual a 0,99 .

Os valores máximos estimados para as variáveis foram de $683,44 \mathrm{~g}$ para uma dose ótima de $218,36 \mathrm{~kg} \mathrm{ha}^{-1}$ de $\mathrm{N}$ e 677,55 g para a dose de $227,85 \mathrm{~kg} \mathrm{ha}^{-1}$, respectivamente para a adubação convencional e fertirrigação.

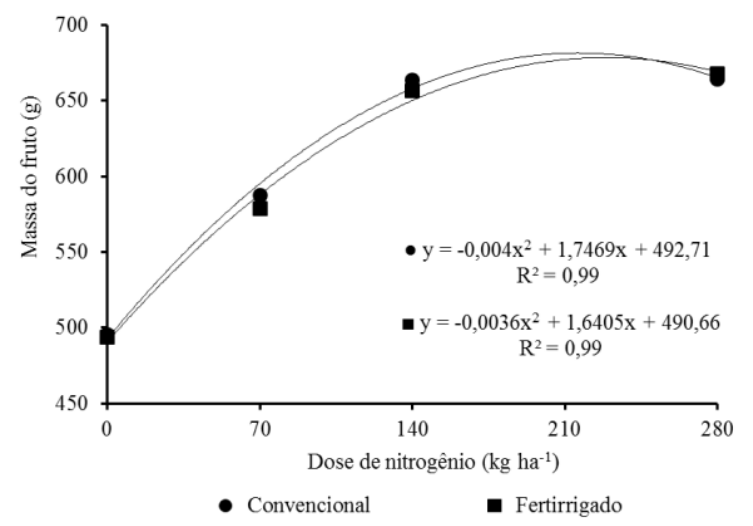

Figura 1. Massa do fruto de abobrinha em função da dose de nitrogênio aplicada pelo método convencional e por fertirrigação.

A resposta encontrada nesse estudo é diferente da observada por Nascimento et al. (2012) em estudo com a cultura do melão amarelo, onde obtiveram resposta linear para a massa dos frutos em função do aumento da 
adubação nitrogenada até $240 \mathrm{~kg} \mathrm{ha}^{-1}$ de N.Apesar de ter sido observada a ocorrência de interação, as respostas da variável em relação às doses de $\mathrm{N}$ foram semelhantes nos dois métodos (convencional e fertirrigação), apresentado valores semelhantes de dose ótima e valor máximo estimado. Essa resposta corrobora com Teixeira, Natale e Martins (2007), quando afirmaram que alguns autores têm demonstrado que, dependendo do tipo de nutriente e da espécie agronômica estudada, nem sempre há diferença significativa entre a nutrição convencional e a fertirrigação.

Para o diâmetro do fruto (Figura 2), o modelo polinomial quadrático apresentou-se como o mais adequado, com $\mathrm{R}^{2}$ igual a 0,99 . $\mathrm{O}$ valor máximo estimado de $77,10 \mathrm{~mm}$ foi obtido com 212,25 $\mathrm{kg} \mathrm{ha}^{-1}$ de N. Já, para a produtividade (Figura 3), o melhor modelo foi o linear crescente com $\mathrm{R}^{2}$ igual a 0,94 , com maior valor estimado de $27.302 \mathrm{~kg} \mathrm{ha}^{-1}$ obtido com a maior dose testada $\left(280 \mathrm{~kg} \mathrm{ha}^{-1} \mathrm{de} \mathrm{N}\right)$.

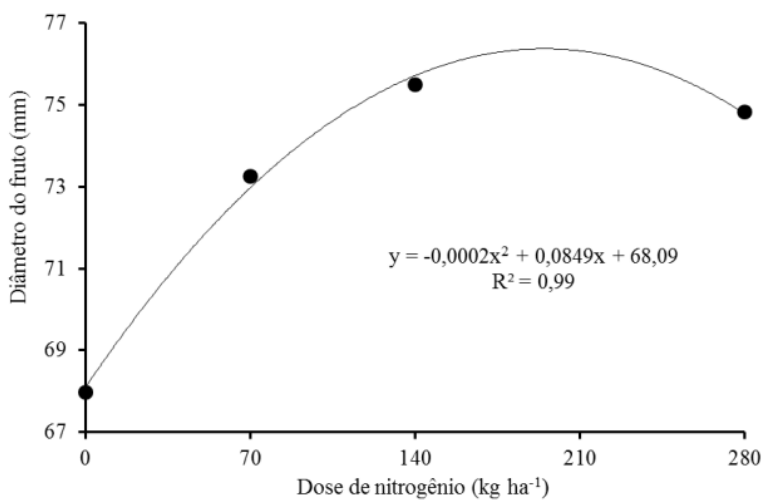

Figura 2. Diâmetro do fruto de abobrinha em função da dose de nitrogênio.

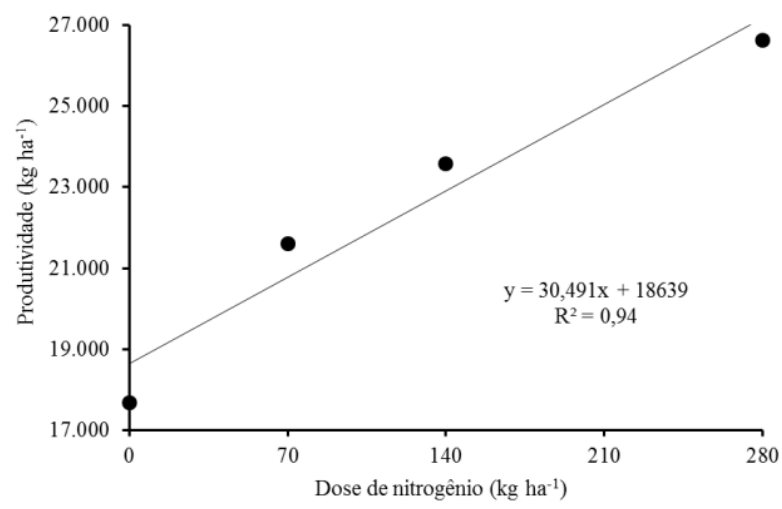

Figura 3. Produtividade de abobrinha em função da dose de nitrogênio.
Com relação ao diâmetro do fruto, a resposta encontrada difere da observada por Azambuja et al. (2015) que avaliaram o comportamento da abobrinha "Caserta" em função de doses de nitrogênio e aplicação de gel hidrorretentor, tendo os autores não observado influência significativa para a variável em questão. Contudo, a dose máxima testada pelos autores citados foi de $200 \mathrm{~kg} \mathrm{ha}$ ${ }^{1}$, enquanto que no presente estudo avaliou-se uma dose máxima de $280 \mathrm{~kg} \mathrm{ha}^{-1}$, podendo essa diferença entre as doses explicar as diferentes respostas encontradas.

A resposta linear observada para a produtividade difere daquela obtida por Pôrto et al. (2012), que ao analisarem a produtividade e o acúmulo de nitrato nos frutos de abobrinha testando cinco doses de $\mathrm{N}$ $\left(0 ; 50 ; 100 ; 200\right.$ e $\left.400 \mathrm{~kg} \mathrm{ha}^{-1}\right)$, obtiveram resposta polinomial quadrática. A produtividade máxima estimada nesta pesquisa foi pouco menor que a obtida pelos autores citados (29.878 $\left.\mathrm{kg} \mathrm{ha}^{-1}\right)$, obtida com uma dose ótima estimada (331 $\mathrm{kg} \mathrm{ha}^{-1}$ de $\mathrm{N}$ ) superior a desta pesquisa. Por outro lado, a resposta desta pesquisa foi semelhante a encontrada por Azambuja et al. (2015), que em experimento com a cultura da abobrinha também obtiveram resposta linear para doses de nitrogênio variando de 0 a $200 \mathrm{~kg} \mathrm{ha}^{-1}$.

Em relação às diferentes respostas de cucurbitáceas à adubação nitrogenada, Antunes et al. (2014) afirmam que elas apresentam muita variação, em função da espécie, da cultivar e do ambiente de cultivo. Nesse caso, no entanto, tais diferenças podem ser explicadas pelo fato dos autores citados terem testado dose de $\mathrm{N}$ superior a maior dose avaliada nesta pesquisa.

Ressalta-se que a dose de $\mathrm{N}$ que proporcionou a maior produtividade nesse estudo $\left(280 \quad \mathrm{~kg} \quad \mathrm{ha}^{-1}\right)$ está acima das recomendadas por Filgueira (2012) $\left(140 \mathrm{~kg} \mathrm{ha}^{-}\right.$ $\left.{ }^{1}\right)$ e por Trani, Passos e Araújo (2014) $(120 \mathrm{~kg}$ $\left.\mathrm{ha}^{-1}\right)$, para a cultura da abobrinha. Se fossem utilizadas estas doses recomendadas, as produtividades nas condições desse trabalho seriam estimadas em $22.971 \mathrm{~kg} \mathrm{ha}^{-1}$ e 22.352 $\mathrm{kg} \mathrm{ha}^{-1}$, respectivamente. Esses valores estão $16 \%$ e $18 \%$ abaixo da maior produtividade 
obtida $\left(27.302 \mathrm{~kg} \mathrm{ha}^{-1}\right)$. Assim, os resultados sugerem ser possível alcançar maior produtividade de frutos na cultura da abobrinha com a aplicação de uma dose de $\mathrm{N}$ maior que a recomendada na literatura, permitindo melhor exploração do potencial produtivo da cultura.

Pelo modelo linear da eficiência de uso da água (Figura 4), estimou-se o maior valor de $68 \mathrm{~kg} \mathrm{ha}^{-1} \mathrm{~mm}^{-1}$ para a maior dose de nitrogênio avaliada $\left(280 \mathrm{~kg} \mathrm{ha}^{-1}\right)$. Enquanto que pelo modelo quadrático da eficiência de uso do nitrogênio (Figura 5) estimou-se a dose de $159,55 \mathrm{~kg} \mathrm{ha}^{-1}$ de $\mathrm{N}$ como responsável pelo máximo valor $\left(54,60 \mathrm{~kg} \mathrm{ha}^{-1}\left(\mathrm{~kg} \mathrm{ha}^{-1}\right)^{-1}\right)$.

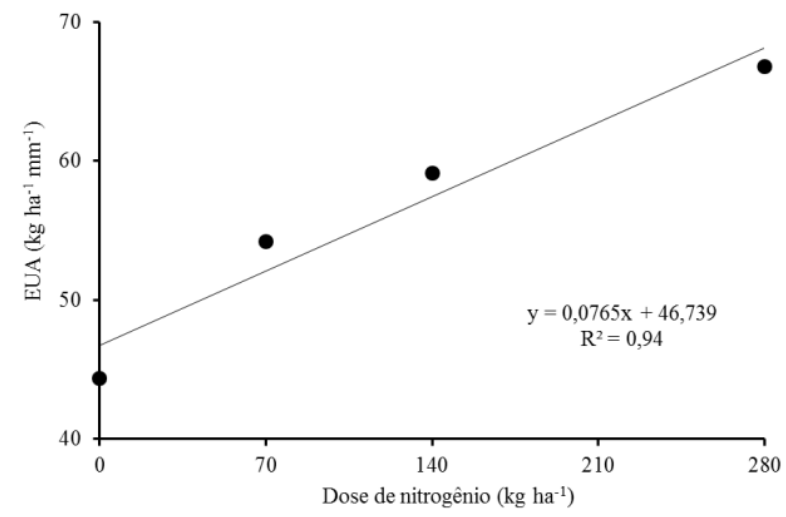

Figura 4. Eficiência do uso da água (EUA) na cultura de abobrinha em função da dose de nitrogênio.

Trabalhando com melancia, Morais et al. (2008) obtiveram resposta quadrática para a eficiência de uso da água em função da dose de nitrogênio, com o maior valor de $221 \mathrm{~kg} \mathrm{ha}^{-}$
$1 \mathrm{~mm}^{-1}$ para um nível de $249 \mathrm{~kg} \mathrm{ha}^{-1}$ de nitrogênio.

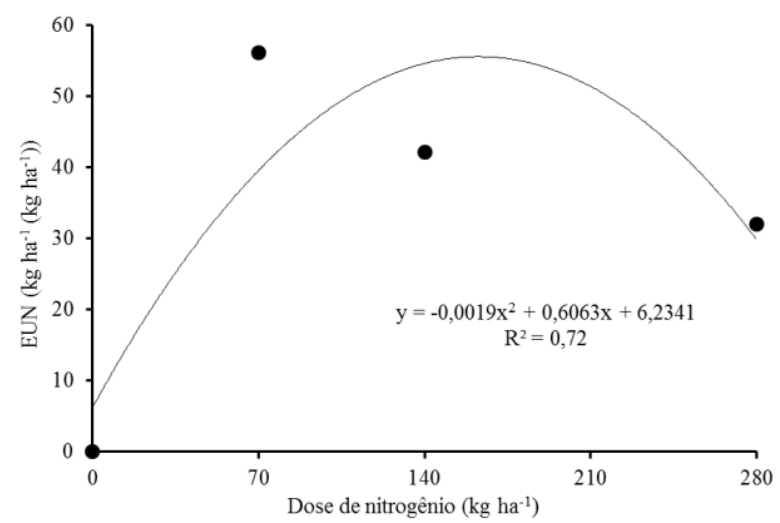

Figura 5. Eficiência do uso de nitrogênio (EUN) na cultura de abobrinha em função da dose de nitrogênio.

O comportamento apresentado pela EUN corrobora com a afirmativa de Majerowicz et al. (2002), quando os autores afirmaram que existem diversos caminhos possíveis para aumentar a eficiência de uso do nitrogênio, sendo mais simples a diminuição da dose de adubo nitrogenado até níveis que sejam produtivos e seguros. Oliveira et al. (2012) afirmam ainda que a partir do ponto de máxima da curva têm-se uma região denotada como não racional para aplicação do insumo.

$\mathrm{Na}$ Tabela 4, estão apresentados os resultados do Valor presente Líquido, Taxa Interna de Retorno e o período "Payback" em função das doses de nitrogênio. Observa-se que todos os tratamentos demostraram ser viáveis economicamente.

Tabela 4. Indicadores financeiros: valor presente líquido (VPL), taxa interna de retorno (TIR) e o período "payback" (PB) em função da dose de nitrogênio aplicada na cultura de abobrinha.

\begin{tabular}{ccccc}
\hline \multirow{2}{*}{$\begin{array}{c}\text { Dose de } \mathrm{N} \\
\left(\mathrm{kg} \mathrm{ha}^{-1}\right)\end{array}$} & $\begin{array}{c}\text { Produtividade estimada } \\
\left(\mathrm{kg} \mathrm{ha}^{-1}\right)\end{array}$ & VPL $(\mathrm{R} \$)$ & TIR $(\%)$ & PB (anos) \\
\cline { 3 - 5 } & 18.639 & $.734,54$ & 9,15 & 4,13 \\
70 & 20.804 & $.494,85$ & 7,74 & 3,82 \\
140 & 22.970 & $.255,17$ & 6,25 & 3,56 \\
280 & 27.302 & $.775,80$ & 3,08 & 3,13 \\
\hline
\end{tabular}

No entanto, houve variação nos indicadores entre os diferentes tratamentos, sendo os melhores valores obtidos para o tratamento em que se aplicou $280 \mathrm{~kg} \mathrm{ha}^{-1} \mathrm{de}$ N.
Além do elevado rendimento do investimento, constatou-se um curto período de tempo para retorno do capital, onde basicamente no terceiro ano o investidor reaveria todo seu recurso. 
Por outro lado, o tratamento testemunha, onde não foi feita aplicação de nitrogênio, proporcionou os menores valores para os indicadores avaliados. Tal observação evidencia que o incremento da produtividade proporcionada pela aplicação de nitrogênio é mais que o necessário para cobrir o aumento nos custos com o insumo, tornando-se atrativo para o produtor o investimento na aquisição e aplicação do adubo.

Analisando a rentabilidade econômica da cultura da melancia em função da frequência de fertirrigação nitrogenada, Fernandes et al. (2014) observaram, por meio da receita líquida, viabilidade para todos os tratamentos estudados, com comportamento crescente para 0 aumento do parcelamento da dose do nutriente.
Pelo comportamento do Valor Presente Líquido ao longo do ano (Tabela 5), observase que o tratamento onde não se aplicou nitrogênio apresentou valor negativo em sete meses do ano, sendo inviável economicamente programar a colheita para tais meses. No entanto, à medida que se aumentou a quantidade de $\mathrm{N}$ aplicada aumentou-se também a quantidade de meses em que o cultivo tornou-se viável, sendo a aplicação de $70 \mathrm{~kg} \mathrm{ha}^{-1}$ viável em seis meses, $140 \mathrm{~kg} \mathrm{ha}^{-1}$ viável em sete meses e $280 \mathrm{~kg} \mathrm{ha}^{-1}$ viável em oito meses.

Assim, pode-se afirmar que a adubação com nitrogênio aumentou a garantia de retorno econômico ao produtor, reduzindo o risco de perdas, à medida que essa dose é aumentada até a quantidade de $280 \mathrm{~kg}$ $\mathrm{ha}^{-1}$.

Tabela 5. Valor presente líquido (VPL) em função do preço de comercialização mensal e da dose de nitrogênio aplicada na cultura da abobrinha.

\begin{tabular}{|c|c|c|c|c|c|}
\hline \multirow{3}{*}{ Mês } & \multirow{3}{*}{$\begin{array}{c}\text { Preço } \\
\text { (R\$) }\end{array}$} & \multicolumn{4}{|c|}{ VPL (R\$) } \\
\hline & & 0 & 70 & 140 & 280 \\
\hline & & \multicolumn{4}{|c|}{ - } \\
\hline Janeiro & 1,12 & $2.659,80$ & $12.668,42$ & $22.677,04$ & $42.694,27$ \\
\hline Fevereiro & 0,70 & $-36.911,38$ & $-31.500,97$ & $-26.090,57$ & $-15.269,76$ \\
\hline Março & 0,95 & $-13.357,10$ & $-5.209,67$ & $2.937,77$ & $19.232,64$ \\
\hline Abril & 1,38 & $27.156,25$ & $40.011,38$ & $52.866,50$ & $78.576,76$ \\
\hline Maio & 0,46 & $34.693,62$ & $48.424,59$ & $62.155,57$ & $89.617,52$ \\
\hline Junho & 1,00 & $-8.646,25$ & 48,59 & $8.743,43$ & $26.133,12$ \\
\hline Julho & 0,67 & $-39.737,89$ & $-34.655,93$ & $-29.573,97$ & $-19.410,04$ \\
\hline Agosto & 0,65 & $-41.622,23$ & $-36.759,23$ & $-31.896,23$ & $-22.170,23$ \\
\hline Setembro & 0,53 & $-52.928,28$ & $-49.379,06$ & $-45.829,83$ & $-38.731,38$ \\
\hline Outubro & 0,82 & $-25.605,33$ & $-18.881,15$ & $-12.156,97$ & $1.291,39$ \\
\hline Novembro & 1,28 & $17.734,54$ & $29.494,85$ & $41.255,17$ & $64.775,80$ \\
\hline Dezembro & 1,33 & $22.445,39$ & $34.753,12$ & $47.060,84$ & $71.676,28$ \\
\hline
\end{tabular}

Vale ressaltar que, buscando o maior rendimento, o produtor deve adotar a adubação com $280 \mathrm{~kg} \mathrm{ha}^{-1} \mathrm{e}$ programar o plantio para que a colheita seja realizada preferencialmente naqueles meses que apresentaram os maiores valores de Valor Presente Líquido (maio, abril, dezembro e novembro), considerando a viabilidade fitossanitária do cultivo.

\section{CONCLUSÕES}

Os diferentes métodos de adubação testados não proporcionaram diferença estatística nas variáveis avaliadas, e somente houve efeito da interação para a massa do fruto.

O aumento da dose de nitrogênio implicou em incremento linear positivo na 


\section{ADUBAÇÃO NITROGENADA POR DIFERENTES MÉTODOS NO CULTIVO DA ABOBRINHA IRRIGADA}

produtividade com o maior valor de $27.302 \mathrm{~kg}$ $\mathrm{ha}^{-1}$ proporcionado pela maior dose ensaiada $280 \mathrm{~kg} \mathrm{ha}^{-1}$ de N.

A eficiência do uso de água teve o maior valor $\left(68,16 \mathrm{~kg} \mathrm{ha}^{-1} \mathrm{~mm}^{-1}\right)$ proporcionado pela maior dose testada $\left(280 \mathrm{~kg} \mathrm{ha}^{-1}\right.$ de $\left.\mathrm{N}\right)$, enquanto que a eficiência de uso do nitrogênio apresentou o valor máximo de $54,60 \mathrm{~kg} \mathrm{ha}^{-1}$ $\left(\mathrm{kg} \mathrm{ha}^{-1}\right)^{-1}$ com dose ótima de $159,55 \mathrm{~kg} \mathrm{ha}^{-1}$ de N.

Todos os tratamentos são economicamente viáveis para exploração agrícola da abobrinha, com os melhores indicadores observados para o tratamento em que se aplicou $280 \mathrm{~kg} \mathrm{ha}^{-1}$ de $\mathrm{N}$.

$\mathrm{O}$ produtor deve programar o plantio para que a colheita seja realizada preferencialmente nos meses de maio, abril, dezembro e novembro, considerando a viabilidade fitossanitária de cultivo.

\section{AGRADECIMENTOS}

A Coordenação de Aperfeiçoamento de Pessoal de Nível Superior - CAPES, pela concessão de auxílio financeiro.

\section{REFERÊNCIAS}

ALMEIDA, E. I. B. et al. Crescimento e marcha de absorção de macronutrientes para a cultivar de melancia Crimson Sweet. Revista Agro@mbiente On-line, Boa Vista, v.6, n.3, p. 205-214, 2012.

ANDRADE JÚNIOR, A. S. de et al. Produção e qualidade de frutos de melancia à aplicação de nitrogênio via fertirrigação. Revista Brasileira de Engenharia Agrícola e Ambiental, Campina Grande, v.10, n.4, p. 836-841, 2006.

ANTUNES, G. et al. Produtividade e qualidade de frutos de pepino africano em resposta à adubação nitrogenada. Revista Ceres, Viçosa, v.61, n.1, p. 141-146, 2014.
ARAÚJO, H. S. et al. Doses de potássio em cobertura na cultura da abóbora. Pesquisa Agropecuária Tropical, Goiânia, v.42, n.4, p. 469-475, 2012.

ARAÚJO, W. F. et al. Crescimento e produção de melancia submetida a doses de nitrogênio. Revista Caatinga, Mossoró, v.24, n. 4 , p. 80-85, 2011.

AZAMBUJA, L. O. et al. Produtividade da abobrinha 'Caserta' em função do nitrogênio e gel hidrorretentor. Científica, Jaboticabal, v.43, n.4, p. 353-358, 2015.

CEASA/CE - Centrais de Abastecimento do Ceará S.A. Análise Conjuntural. 2015. Disponível em: <http://www.ceasace.com.br/index.php/analise-conjuntural $>$.

Acesso em: 20 abr. 2015.

COELHO, E. L. et al. Qualidade do fruto de melão rendilhado em função de doses de nitrogênio. Bragantia, Campinas, v.62, n.2, p. 173-178, 2003.

COSTA, A. R. da et al. A cultura da abobrinha italiana (Cucurbita pepo L.) em ambiente protegido utilizando fertirrigação nitrogenada e potássica. Irriga, Botucatu, v.20, n.1, p. 105-127, 2015.

COUTO, M. R. M. et al. Transformações de dados em experimentos com abobrinha italiana em ambiente protegido. Ciência Rural, Santa Maria, v.39, n.6, p. 1701-1707, 2009.

EMPRESA BRASILEIRA DE PESQUISA AGROPECUÁRIA (EMBRAPA). Sistema brasileiro de classificação de solos. 2.ed. Rio de Janeiro: Embrapa Solos, 2006. 306 p.

FERNANDES, C. N. V. et al. Frequências de fertirrigação nitrogenada e fosfatada na rentabilidade econômica da melancia. Revista Brasileira de Agricultura Irrigada, Fortaleza, v.8, n.3, p. 270-279, 2014. 
FILGUEIRA, F. A. R. Novo manual de olericultura. 3. ed. Viçosa: Editora UFV, 2012. $421 \mathrm{p}$.

KOPPEN, W. Dieklimate dererde-grundrib der kimakunde. Berlin, Walter de gruyter verlag, 1923.

MAJEROWICZ, N. et al. Estudo da eficiência de uso do nitrogênio em variedades locais e melhoradas de milho. Revista Brasileira de Botânica, São Paulo, v.25, n.2, p. 129-136, 2002.

NASCIMENTO NETO, J. R. do. et al. Formas de aplicação e doses de nitrogênio para o meloeiro amarelo no litoral do Ceará. Irriga, Botucatu, v.17, n.3, p. 364-375, 2012.

NOGUEIRA, F. P. et al. Crescimento e marcha de absorção de nutrientes da melancieira fertirrigada com diferentes doses de N e K. Revista Verde de Agroecologia e Desenvolvimento Sustentável, Pombal, v.9, n.3, p. 35-42, 2014.

OLIVEIRA, M. V. A. M.; VILLAS-BÔAS, R. L. Uniformidade de distribuição do potássio e do nitrogênio em sistema de irrigação por gotejamento. Engenharia Agrícola, Jaboticabal, v.28, n.1, p. 95-103, 2008.

OLIVEIRA, P. G. F. de. et al. Eficiência de uso dos fatores de produção água e potássio na cultura da melancia irrigada com água de reuso. Revista Brasileira de Engenharia Agrícola e Ambiental, Campina Grande, v.16, n.2, p. 153-158, 2012.

PÔRTO, M. L. A. et al. Produtividade e acúmulo de nitrato nos frutos de abobrinha em função da adubação nitrogenada. Bragantia, Campinas, v.71, n.2, p. 190-195, 2012.
QUEIROGA, R. C. F. de. et al. Influência de doses de nitrogênio na produtividade e qualidade do melão Cantalupensis sob ambiente protegido. Horticultura Brasileira, Vitória da Conquista, v.25, n.4, p. 550-556, 2007.

SILVA JÚNIOR, M. J. et al. Acúmulo de matéria seca e absorção de nutrientes de meloeiro "pele de sapo". Revista Brasileira de Engenharia Agrícola e Ambiental, Campina Grande, v.10, n.2, p. 364-368, 2006.

SILVA, M. V. T. da. et al. Diagnose foliar da abóbora submetida a diferentes níveis de salinidade e doses crescentes de nitrogênio. Agropecuária Científica no Semiárido, Patos, v.9, n.2, p. 118-125, 2013.

SOUSA, G. G. de. et al. Adubação potássica aplicada por fertirrigação e pelo método convencional na cultura do amendoim. Revista Brasileira de Engenharia Agrícola e Ambiental, Campina Grande, v.17, n.10, p. 1055-1060, 2013.

TEIXEIRA, L. A. J.; NATALE, W.; MARTINS, A. L. M. Nitrogênio e potássio via fertirrigação e adubação convencional-estado nutricional das bananeiras e produção de fruto.

Revista Brasileira de Fruticultura, Jaboticabal, v.29, n.1, p. 153-160, 2007.

TRANI, P. E.; PASSOS, F. A.; ARAÚJO, H. S. de. Calagem e adubação da abobrinha italiana (de moita) (Cucurbita pepo), abóbora brasileira (Cucurbita moschata), moranga (Cucurbita maxima) e abóbora japonesa (híbrida). Campinas: Instituto Agronômico e Fundação IAC, 2014. 8 p. (Boletim Técnico). 